\title{
THE GIARDINO DELLE CAMELIE IN THE BOBOLI MONUMENTAL GARDEN: INTEGRATED SURVEY, STRUCTURAL REINFORCEMENT AND RESTORATION PROJECT OF THE ARCHITECTURE, THE DECORATIONS AND THE HYDRAULIC SYSTEM
}

\author{
G. Tucci ${ }^{1}$, P.Ruggieri ${ }^{2}$, M. Mazzoleni ${ }^{3}$, A. Conti $^{1}{ }^{2}$ L. Fiorini ${ }^{1}$, F. Panighini ${ }^{1}$ \\ ${ }^{1}$ Dept. of Civil and Environmental Engineering, University of Florence, via Santa Marta 3, Florence, Italy \\ grazia.tucci@unifi.it, arch.a.conti@gmail.com, lidia.fiorini@gmail.com, francesca.panighini@gmail.com \\ ${ }^{2}$ Gallerie degli Uffizi, Piazzale degli Uffizi n. 6, Florence, Italy \\ paola.ruggieri@beniculturali.it \\ ${ }^{3}$ Engineer and architect, freelance \\ studio@mnlab.it.
}

KEY WORDS: Giardino delle Camelie, Giardino di Boboli, Artificial grottoes, Ancient hydraulic systems, Laser scanner, Photogrammetry, Mesh modelling, Structural reinforcement

\begin{abstract}
:
The Boboli Monumental Garden, from the first half of the 17th century, houses "secret" spaces such as the Giardino delle Camelie, a secluded space reserved only for members of the Medici family. The particular configuration, both in plan and height, and the state of conservation of the Garden required a thorough survey with photogrammetric and laser scanner techniques as a preliminary investigation for the restoration and structural reinforcement project. The survey, together with a careful examination of the present conditions, the historical and archival research, the geognostic investigations enabled to investigate the object in its many specificities and to proceed to the following analysis and design.

Starting from the 3D model, it has been possible to extract all the 2D views for the rendering of the survey and project drawings and to achieve countless qualitative and quantitative information on the structures, otherwise difficult to deduce, useful both for the project and restoration.
\end{abstract}

\section{THE GARDEN: SHAPE AND COMPOSITION}

The Giardino delle Camelie is presented in the double consistency of a unitary organism and an organic part of the larger architectural and landscape complex of the Pitti - Boboli museum system.

The garden has a surface area of 304 square meters, a total length of $69 \mathrm{~m}$ and a width ranging between $1.50 \mathrm{~m}$ and $6.60 \mathrm{~m}$ and is located on a long and narrow strip of land, on the west side of Palazzo Pitti (to which it is connected by two buttresses), against the retaining wall of the Piazzale della Meridiana.

Despite important changes over the centuries, the garden still preserves the original seventeenth-century structure and an important collection of camellias started in the nineteenthcentury.

The garden consists of two distinct parts: a "public" part, related with Boboli and marked by an access path bordered by flowerbeds, which starts at the main gate and ends at the passthrough Grotto; a "private" part, related with the Palace and characterized by the "secret garden" that, once crossed the grotto, appeared in the past in its glory with a paved path lined with a double row of flower beds with camellias, two small oval fountains, benches and bases for supporting the terracotta pots that once allegedly embellished the garden. The path reaches the space in front of the Grotticina lorenese and the loggia of the Palace connected to private rooms.

In the Garden there are the same aesthetic and stylistic themes typical of the Boboli Gardens: the motif of the naturalistic structure of the seventeenth-century Grotto and specifically the idea of an ephemeral structure close to collapse; the motif of the niche/grotto, still showing some traces of the original layout in the structure behind the grotto, which, although reworked in 1765 and completed in 1819, still preserves today the decorations with wall paintings and the fountain with a statue.

The Medici layout of the garden was radically changed during the Lorraine period, not only in its botanical component but also in the plano-altimetric configuration.

Today the Giardino delle Camelie is in an advanced state of decay; a major structural instability mainly affects the lower wall bastion, which has extensive and clear downstream slope mechanisms. This is certainly the most critical issue for the Garden and affects its safety and use.

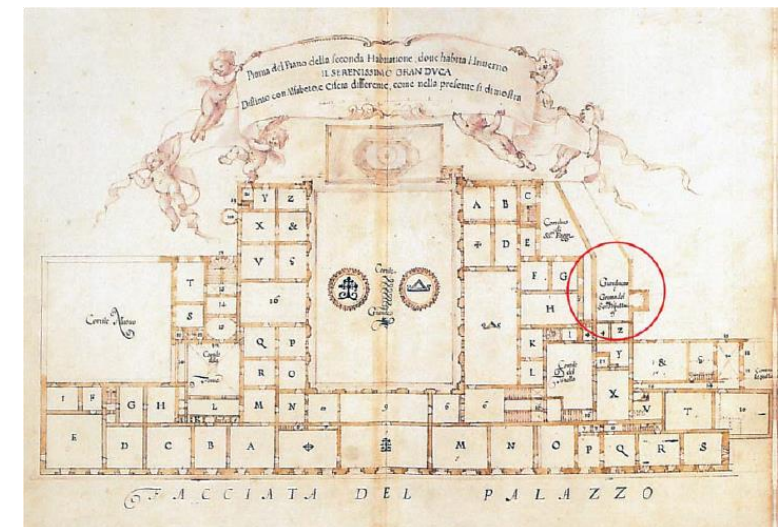

Figure 1. Giacinto Maria Marmi, Pianta della Seconda Habitazione, dove Habita l'inverno il Serenissimo Gran Duca, 1662 c. Firenze, Biblioteca Nazionale, Magliab. II.I.284 
Also, the upper wall and all the architectural and decorative elements of the Garden and its furniture are precarious.

The state of conservation of the decorated surfaces of the Grotto and Grotticina lorenese is particularly serious.

\section{THE GARDEN: THE HISTORY}

The Garden is one of the rare examples of private places created inside Boboli, or "secret gardens" reserved for some members of the Grand Duke's family, where rare citrus or exotic plants were usually cultivated (Contini, Gori 2004).

It was built around the mid-seventeenth century, in continuity with the apartment of Prince Mattias, the younger brother of Grand Duke Ferdinando II de 'Medici, located on the first floor of the mezzanine in the west wing of the building. The first mention of the Giardinetto del Serenissimo Principe Mattias dates to May 1661; in the occasion of the wedding celebrations between the Grand Prince of Tuscany, later Grand Duke Cosimo III, and Marguerite Louise d' Orléans, a wooden walkway has been built across the garden in order to transport a theatrical equipment. At the end of April 1663, there is another mention about the reconstruction of the "wall above Prince Mattias' Garden in Boboli at the exit of the Theatre" (Capecchi 1993). An inventory of 1663 describes the garden, where there are "cassettoni murati", or flowerbeds built on retaining walls, where Cardinal Giovan Carlo, brother of Grand Duke Ferdinando II and Mattias de' Medici, had been authorized to plant any kind of bulbous plants, including "tulips, anemones and hyacinths" (Galletti 1999).

In 1688, for the marriage between Grand Prince Ferdinando and Violante of Bavaria, the apartment reserved for the princess and the private garden were renovated. Biagio and Diacinto Maria Marmi, architects and attendants to the Guardaroba, designed a small portico with an above gallery, which overlooks the final part of the garden with the aim of separating the princess rooms at the main floor (Baldini Giusti 1991).

The architectural features that still characterize the garden today date back to this period, although, compared to a drawing in the Gabinetto dei Disegni e delle Stampe degli Uffizi, the entire composition appears simplified, without the smaller fountains in the flower beds and two niches in the first part of the side wall. The garden was divided into compartments delimited by a stone border, with a vase stand at each corner, benches and two small oval basins.

Halfway along the route there is a Grotto, which separates the most hidden and private part of the Garden from the one connected with the Boboli Park. Various preparatory drawings by Marmi show the evolution from an initial project in a classical style to the current appearance, where the naturalistic and apparently precarious elements prevail. (Baldini Giusti 1991).

The Grotto is formed by three arches of different sizes (Cappa, Pettini, 2008). It is made of irregularly shaped stone elements, built in apparently random mode and pretending to be a natural grotto, or a building near to collapse, an ephemeral structure, according to the fashion of the time. The barrel vault inside is decorated with geometric and naturalistic motifs, which now have some gaps (Nizzi Grifi 2003).

Another architectural element of the garden is the small space carved into the side wall, already represented in a seventeenthcentury map and modified in the Lorraine age which is now called Grotticina Lorenese (fig 1).

In the second half of the eighteenth century, the garden underwent a thorough transformation that radically changed its architectural, structural and botanical aspect. In 1789, the Piazzale della Meridiana was built, raising the ground level of the Anfiteatro and some vaults were built for supporting the embankment on the upper retaining wall, with the consequence of reducing the area of the Giardino delle Camelie. As a result of this transformation its botanical aspect changed: the level of the garden became lower than the surrounding areas and the garden become shady and no longer suitable for the cultivation of bulbous flowers, but more apt for the cultivation of camellias (called to "flowering shrubs") from which we owe the etymology of the garden.

In the Lorraine period, the Garden was mentioned as "garden of S.A.R.", or "small garden of the sovereign" (Gori 2003), because it was in the wing of the Palace that Pietro Leopoldo had reserved for his apartments and for his private secretariat. The detailed descriptions taken from the historical sources, refer both the architectural part and the floral furnishings; they include the loggia, the two small grottoes, one of which with "marine incrustations, Niobi and stones", flowerbeds with polychrome terracotta vases "sculpted with low reliefs of festoons and leaves" and stone benches. About vegetation, the mention of "flowering shrubs" suggest that the first plantation of camellias dates back to this period (Contini, Gori 2004).

Immediately after the arrival in Florence of Pietro Leopoldo, the first gardener Agostino Ricci in 1766 proposed some works to consolidate some portions of degraded masonry that made the place unsafe. (Gori 2003).

The Garden is represented in the Cabrei of 1775 conserved in Prague in the archive Archivio Familiare degli Asburgo Lorena di Toscana; in the map 5 of the series Palazzo Pitti, Boboli e loro pertinenze the Garden is identified with n. 6, the Grotto with "encrustations" with $\mathrm{n} .7$, the Loggia with n. 9.

A series of twenty-eight drawings attributed to Pasquale Poccianti, architect of the Scrittoio delle Regie Fabbriche, dated between 1796 and 1802, show the hydraulic system of Palazzo Pitti (Capecchi 2004) and they are a fundamental document for the assessment of the state of the Garden at the end of the 18th century.

In the second Lorraine period, the Grotto was decorated with wall paintings by Giuseppe Gherardi around 1819 . Monochrome figures of herms, medallions and geometric ornaments leave space on the two side walls for the representation of nymphs or Bacchaeans, while some cherubs with flowering branches in their hands overlook from the ceiling vault depicting the sky. The Grotticina lorenese houses a fountain in white marble, dating back to the first half of the 19th century and composed of a cup on a pedestal with a statue, also in marble, on a capital-shaped base with three masks connected by festoons on each side, of which the central one is used for the outflow of water. The statue, probably of ancient manufacture with modern restorations, depicts Hygieas, the daughter of Asclepius, or Epio, goddess of health and hygiene (Cappa, Pettini, 2008).

On the cultivation of camellias in Boboli, the first certain information dates to 1818 , when the inventory of the Botanical Garden was drawn up, while during the nineteenth century the collection underwent a considerable increase (Cappa, Pettini, 2008). Taking advantage of the existing flowerbeds, in the first half of the 19th century the planting of a row crop of camellias started (Galletti 1999, 77), giving the Garden its current name.

\section{THE SURVEY}

\subsection{The survey: introduction}

The theme of the survey of a garden requires at first an attempt, however complex, to define what a garden is, at least considering the historical garden in the European context. The 
"Carta italiana per il restauro dei giardini storici ", a response by Italian experts to the "Florence Charter" drawn up by the International Committee of Historical Gardens ICOMOS-IFLA, defines the historical garden as "a multimaterial ensamble, designed by man, mainly realized with living material that stands on (and modifies) an anthropic territory, a natural context. As a material artefact, it is a work of art and, consequently, a cultural asset, an architectural and environmental resource, the heritage of the entire community that benefits from it".

The Carta Italiana, recalling the 1964 Venice Charter, stresses that restoration "must be identified with an intervention of conservation, and this aim must be achieved and guaranteed over time through a process of continuous, planned, timely maintenance".

Article 4 states that knowledge is necessary "to protect and conserve", indicating the need of studying the garden "in all its components (architectural, botanical, hydraulic, geological, topographical, environmental, etc..) both through documents and historical and literary sources, and through surveys, topographic and ancient cadastral ones, as well as any other iconographic source" (Dezzi Bardeschi 1989, ICOMOS). Among the required investigation areas, spatial information was therefore included, also suggesting the use of the topographic method, which was, actually, the most appropriate in those years.

Nevertheless, the bibliography on the instrumental survey of historical gardens is very limited (Tucci 1999, Liang, H et al. 2018, Sette et al. 2016), in relation, especially in recent years, to the broader theme of the documentation of the $\mathrm{CH}$ (El-Hakim et al. 2004, Grussenmeyer et al. 2011, Balletti et al. 2015).

The above mentioned Garden Charters are the result and the summary of a period, between the $70 \mathrm{~s}$ and $90 \mathrm{~s}$, of great attention to this topic (Zangheri 2008, ICOMOS 2016). The culture of information technology and the techniques of instrumental survey, however, were still episodic and perceived with suspicion: the rigidity of first computer systems was interpreted, behind the alleged objectivity of an automatic data processing, as an attempt to sacrifice the traditional and typically human activity of selecting the salient points of real world for translating them into graphic symbols (De Carlo 1992).

Even if the current survey tools allow a more faithful representation of the organic geometries, it must be admitted that the present methods of acquisition and rendering are more optimized for the documentation of built elements than for natural and vegetal ones. The present technologies that produce a high-density sampling of surfaces are aimed at accurately and rigorously describe complex geometries, such as those of the architecture of the Mannerist gardens (Tesi et al 2017), but only if they are motionless and not particularly thin, because in this case the signal-noise ratio is unfavourable.

It is therefore possible to measure the overall size of a tree or a vegetation mass with greater accuracy than with traditional techniques (Tucci et al. 2014) but the realistic description of the more minute vegetal elements (such as leaves and twigs) may require an unreasonable amount of work considering that they are intrinsically ephemeral and periodically regenerated elements (Kumazaki et al.2016, Boulanger et al. 2008).

\subsection{The survey project: critical issues and choices}

The case study, as already described in paragraph 2 , concerns a garden with a majority of built elements than cultivated ones. The Soprintendenza that coordinates the restoration and consolidation project required, as support for the project itself, a geometric and material description focused on the structure of the retaining walls, the architectural components and the documentation of the visible elements of the hydraulic system. In these circumstances, the botanical component of the garden was, paradoxically, a disturbing element, as the camellia plants leaning against the retaining wall were particularly lush in spring and prevented a clear vision of the walls. The site geometry was also critical: it is a thin strip eighty metres long and about nine metres wide between retaining walls with a maximum height of about seventeen metres in the Grotticina Lorenese area. Lighting conditions are sub-optimal (shady or backlit) for most of the day and some rooms were almost inaccessible, such as the one below the Grotto or the corridor behind the Grotticina Lorenese, which is cluttered with materials.

The survey project proceeds "from the general to the particular": first, a topographic network has been designed for referencing the data acquired with laser scanner. Then, photogrammetry was considered the most suitable technique to accurately describe the wall surfaces, while laser scanning was preferred for the overall survey of the garden. The use of a scanner with an integrated camera that also acquires HDR spherical panoramas, thus obtaining for each point not only the $\mathrm{X}, \mathrm{Y}, \mathrm{Z}$ coordinates but also the corresponding RGB values, has also made it possible to integrate data obtained with the two techniques from a chromatic point of view and to eliminate reciprocally the inevitable gaps that occur in such conditions.

\subsection{Topographic network}

The geometry of the topographic network had to consider the shape of the space to be surveyed and a construction site on the terrace of the Fontana del Carciofo prevented the access to the best point view of the entire area. A traverse of 7 vertices was measured, permanently materialised, for any subsequent survey campaigns, from which the targets for the alignment of the scans were measured. In the first section, between the access staircase and the Grotto, it was possible to measure a closed traverse, while in both the next section and in the portion downstream of the lower retaining wall it was necessary to proceed with branches. The redundancy of the observations, repeated twice in conjugate mode for each of the measured directions, has been ensured, so that even the measurement scheme adopted can be considered as a close traverse as it was measured in "outward and return".

\subsection{Laser scanner acquisitions}

Fifty-one scans were carried out, the first 41 inside the garden and along the lower retaining wall, with a resolution of $6 \mathrm{~mm}$ at $10 \mathrm{~m}$, the next 10, carried out from the Piazzale della Meridiana and by some windows of Palazzo Pitti, with resolution of $3 \mathrm{~mm}$ at $10 \mathrm{~m}$, corresponding to a final average resolution of about $4 \mathrm{~mm}$ on the object. The measurements were extended to the entire area; however, attention was focused on the retaining walls and architectural elements (fig 4).

It is known that the intrinsic reference system of each scan is in the centre of the instrument. In order to align them according to topographic reference system, a roto-translation was performed, identifying as homologous points the centre of the targets (measured with the total station) and other natural points. The pre-alignment performed in this way was then optimized using an ICP (Iterative Closest Point) algorithm, at the end of which the absolute average alignment error was $2 \mathrm{~mm}$. The endpoint model consists of 2,291,290,164 points. Then some editing was done for eliminating outliers and other irrelevant elements. The 
presence of the plants, hiding the walls, required an exuberant number of scans and despite this, the recognition of architectural elements was sometimes difficult because of the lack of data in the shadows.

\subsection{Photogrammetric acquisitions}

Considering the spatial configuration of the garden (which obliges to take images from close points of view), the above described criticalities and the impossibility to use a UAV system, it was not possible to adopt a common criteria for the acquisition project in the whole area. It was therefore decided to achieve an average GSD, less or equal to $3 \mathrm{~mm}$, and to select the lens with the most appropriate focal length for each portion of the walls, provided that the overall height had to be totally included in the longest side of the image. The baseline was established with more than $80 \%$ overlap between adjacent images. To the images with axis orthogonal to the wall, some other converging images were added, oriented both towards the walls and furniture elements for eliminating, as far as possible, the shadow areas and especially for detecting, as complete as possible, the walls behind the camellia plants. The images were taken with a Nikon D700 camera with a $24 \times 36 \mathrm{~mm}$ sensor and a resolution of $4256 \times 2832$ pixels, with Nikkor prime lenses with a nominal focal length of 50,24 and $20 \mathrm{~mm}$.

1820 images have been taken, then edited to adjust their radiometric characteristics. The photogrammetric workflow involves first the exterior orientation of the images and then the insertion of Ground Control Points (preferably measured targets) for the optimisation of the interior orientation together with the scaling and referencing of the photogrammetric model. The presence of the precious camellias and, above all, the lack of an elevation system for uniformly positioning the targets on the entire surface of the two retaining walls, requested to use as GCPs and Check points also some natural points whose coordinates were extracted from the point clouds obtained with laser scanning. A total of $53 \mathrm{GCPs}$ were measured and a further 6 points were used as checkpoints. At the end of processing, a model of 224,366,734 points was obtained.

\subsection{Output: 2D drawings and mesh models}

For the preparation of CAD drawings in orthogonal projections and true orthophotos it is essential to identify the projection planes parallel to the surface to be represented and then define a local reference system for each of them. In the case of the Giardino delle Camelie it was a heavy operation because both the upper and lower retaining walls follow a polygonal path and it was necessary to define 12 different local reference systems, all of them connected to the global topographic reference system. Such a rich points model has made it possible to relate the garden with its context, therefore in the CAD works has been rendered, even if in a schematic way, also some parts of Palazzo Pitti. In CAD drawings, the architectural elements of the garden have been draught in their real consistency, without any integration of the gaps.

The final drawings include orthophotos, i.e. images without perspective distortion and orthogonally projected to the reference plane, which average GSD is $0.0025 \mathrm{~m}$.

In some cases, e. g. for the plan of the portico at the end of the garden or the one of the grotto, the orthophotos have been integrated with orthoimagery extracted from the model of points obtained by scanning.

From the photogrammetric point model, after some editing, a mesh surface model of 44 million polygons was obtained, then decimated to 28 million (fig. 3). From the surface model, metrically correct orthogonal views can be extracted and used for rendering the background view in 2D works (plans and sections). All the deformations on the main masonry structures and surfaces are visible on the model. Moreover, after an adequate decimation, they can be used for online visualization.

\section{ANALISIS OF THE STRUCTURAL CONSERVATION}

Historical research underlines that there were structural problems in the garden already in the Lorraine period. The presence of two buttresses in the lower wall of the Garden, shows that the stress induced by the push of the embankment is a problem that has affected him throughout all its history.


Figure 2. Examples of the instabilities in the garden

At present there are many areas with extensive severe static damages, among others:

- Large cracks in the central area of the lower wall bastion, beyond the Grotto, together with severe deformations;

- Passing through fractures in the lower wall bastion and the masonry portal at the entrance to the Garden;

- Differential settlements in the sandstone slab paving close to the lower wall;

- Serious cracks in the wall structures of the Grotto.

Almost all the instabilities can be attributed to the lower wall bastion, and its inability to locally counteract the forces exerted by the embankments of the Garden.

These events are concentrated mostly at the entrance and in the central part, close to the Grotto (fig 2). In both cases it is evident that the wall is fatigued for the thrust of the ground and show out-of-floor rotations that induce further instabilities in the structures. 
In correspondence with the areas of instability of the lower wall bastion there are serious settlements of the floors and architectural structures, which have resulted in significant cracks in the wall structure and breakage of the stone slabs of the floor.

\subsection{The state of architectural conservation and of the decorated surfaces}

An advances degradation is present on almost all stone surfaces and decorated architectural surfaces due to the constant exposure to the water. In particular in the Grotto: the internal plaster surfaces, partially painted in the vaulted ceiling, are heavily degraded and locally compromised because of the copious infiltrations that pass through the roof, which has an unusual structure with a counter slope towards the centre, apparently without an effective system of protection and disposal of rainwater.

The external walls of the grotto, built with apparently random slabs and sandstone blocks, are affected by the deterioration of the joints of mortar. The ingenious system of retaining the stone blocks appears precarious. This is done with very thin and unstable copper wires that release oxide percolations on the stone.

In the Grotticina Lorenese the decorative and architectural components, mostly the partitions on the facade, made of plaster and sandstone elements, are in bad state of preservation. The projecting parts of the facade are very compromised and have large gaps that locally reach the wall support. The plaster finishing layer on flat masonry is very flimsy and inconsistent. The sandstones are disjointed, with local detachments and deep gaps. Inside the exedra the pictorial film appears incohesive, locally affected also by marked defects of adhesion to the support and by chromatic alteration of the colours. Most of the pictorial decorations were probably restored in the second half of the nineteenth century, especially the decorations with plant spirals and floral motifs on the architectural bands. The pictorial decorations are in a very precarious condition and require an urgent conservation to ensure their stabilisation.

\section{HYDRAULIC SYSTEM}

Water is the backbone of a garden and can be divided into three parts: the water supply, the branch of the pipes with water games and fountains and finally the system of drainage and drainage of water.

Adduction: the water features of the Giardino delle Camelie were operated using the water from the San Leonardo spring dating back to the Medici period (1553-1556) and presumably also the water from the Merlaia spring at the end of the 18th century. The water from the San Leonardo spring, directed into the Conserva delle Trote, supplied the 17th century water supply to Boboli in three main directions. In one of the three directions, the water was conveyed from the Conserva delle Trote to the cistern called Bottino dell'Edera located on the Piazzale della Meridiana, in a position above the Giardino delle Camelie. However, the water from the Merlaia spring also flowed into the Bottino dell'Edera, as can be read from the Pianta de Condotti che portare l'acqua all'Imperial Palazzo de' Pitti e Giardino di Boboli e altri luoghi in detto Giardino by Giuseppe Ruggieri (1757). In that map, at n. 17 is identified the room "where are the branches for the jokes of the Grotto and Garden of the Violante Princess". The room is located at Piazzale della Meridiana next to the staircase that led from the Prato to the Palace (the staircase was then demolished in 1789 when the ground was raised for building the current Piazzale della Meridiana). The Bottino dell'Edera was then replaced with another cistern, the "Deposito Falasconi". Since then, the water supply of the Garden of the Camellias comes exclusively from the San Leonardo spring and only one point of supply has been left in the niche of the Grotticina Lorenese.

The duct branch: one of the water supply points was inside the Grotto where a fountain was inside a niche and there are traces of the ancient piping and water features on the floor, as the bored holes in the floor. They are visible in a cross section drawing of the Grotto by Poccianti (Pasquale Poccianti (attr.), Prospect and section of the Grotto located in the Giardinetto del Real Sovrano, 1796 - 1802. table XVII. Pencil drawing, Indian ink, brush and watercolour on white paper, Florence Archaeological, Fine Arts and Landscape Superintendence Archive for the metropolitan city of Florence and the provinces of Pistoia and Prato). The drawing clearly shows a series of hydraulic pipes in the gallery below the grotto, and nozzles for water in its floor, which were the mentioned water game. Other water supply points are represented by the two small oval fountains, now in a state of advanced decay, and the fountain located in a niche in the Grotticina Lorenese. The project will include a restoration of the existing hydraulic system elements, for the reactivation of the ancient water features in the Garden and a new irrigation system for the Camellias.

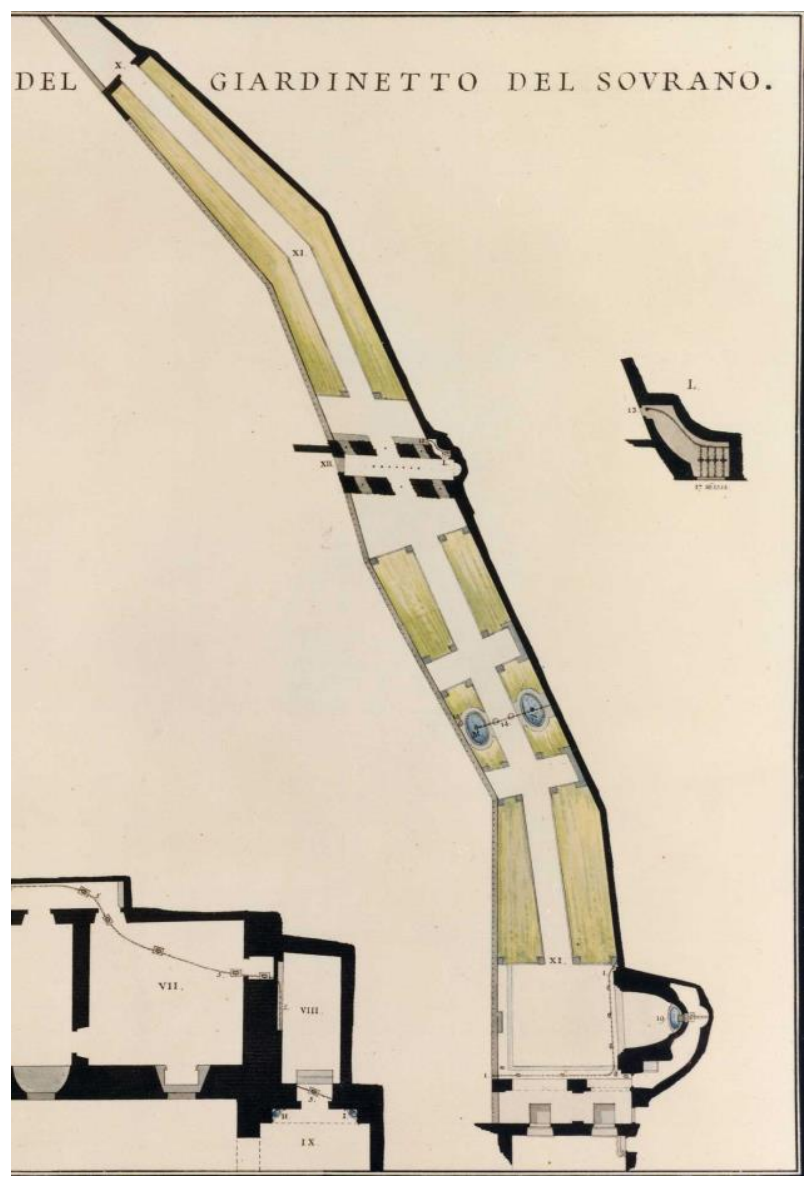

Figure 3: Pasquale Poccianti (attr.), Pianta del Cortile della Dispensa, e suoi annessi, e del Giardinetto del Sovrano , 17961802

The water drainage system: the decay of the Garden is linked to the malfunction of the current drainage of water and is one of the main points of the restoration project of the hydraulic system. In fact, it is under design an integration of the current drainage system for the percolation of water through the 
embankments, in order to improve its flow and leakage through specially created pipelines, and to prevent harmful overpressures on the inner face of the retaining wall and seepage through the wall and plaster. The installation of suitable drains will achieve this aim. The drainpipes will be arranged in a sub-horizontal position with a suitable slope towards the outside in order to allow a correct collection and disposal of the water present in the ground. The drains will be set drilling, as much as possible, in the current openings of the wall.

\section{CONSOLIDATION AND RESTORATION}

\subsection{Structural consolidation: a summary of interventions}

The choices of the consolidation project are the result of the conviction of the absolute necessity to put first, in the proposed interventions, the objectives of compatibility, reversibility, recognizability and minimal intervention, in order to ensure maximum respect and consistency of the intervention with the physical, aesthetic, and cultural essence of the monument.

Some of the planned structural consolidation works are briefly described below.

- In the southern area, at the entrance to the garden, a new system of wall bracing will be created by laying horizontal tie rods under the floor, anchored in the rock bank on which the upper wall bastion is set and bound to the masonry by means of a horizontal iron bar for the load distribution;

- In correspondence with the severely damaged entrance portal, it is planned to carry out localised operations to sew up the masonry fabric, with partial reconstruction of the same in correspondence with the large lesions, and insertion of stainless-steel pins arranged between the lesions to guarantee an effective connection of the unstable masonry parts. The cornice will be reinforced in two places with stainless steel helical tierods under the plaster, to create a "reinforcement ring" at the top of the portal.

- In the central area after the Grotto it is necessary to create an effective system of contrasting the thrusts of the embankment, realized also in this case on two levels, because of the greater height of the wall. The system will be implemented with two lines of active rods in soil/rock.

The tie rods will be of the "permanent" type and will allow, by means of a "post-tensioning" operation following the anchoring in rock, to impress immediately on the bastion wall a balancing stress of contrasting thrusts behind. In order to allow the distribution on the masonry of the concentrated stresses induced by the new strengthening elements, the formation of a reinforcement of the masonry is expected by laying on the outer face of a low thickness BFRP (basalt fibre) bidirectional mesh applied with structural mortar based on natural hydraulic lime nhl 3.5 and pozzolana.

\subsection{The restoration: summary of interventions}

The conceptual and methodological approach that characterizes the project is derived from the Brandi's restoration theory, where the Restoration is defined "the methodological moment of recognition of the work of art in its physical consistency and in its double aesthetic and historical polarity, with a view to its transmission to the future" (Brandi, 1963).

About the surface restoration, this orientation favours a "critical-conservative" approach, according to the latest developments in the discipline.

The restoration will therefore be conservative, and will prefer the maintenance of the original material, compatible with the state of deterioration and the degree of impairment of the plasters in the different areas of the retaining walls, while in areas of instability will necessarily be conducted targeted interventions of structural reinforcement and therefore it will be necessary to locally remove the existing plasters.

On all the other areas of the masonry, any mortar removal operations will be limited to the most degraded areas, characterized by a total impairment of their physical and mechanical properties. For all the other parts, the conservation operations will be carried out. Specifically, for the Grotto and Grotticina Lorenese the following interventions are planned: Grotto: at first, the most urgent operations of safety and preconsolidation of the decorated internal surfaces in precarious conditions of conservation will be carried out. Targeted fastening operations will therefore be carried out with Japanese paper glazes and/or gauzes with acrylic resins in solution, in the areas of greatest precariousness, or pre-consolidation will be carried out with brush impregnation of ethyl silicate.

At the same time, therefore, the main triggering factors of the present pathologies will be eliminated:

i) revision and possible integrations of the brick covering, with possible waterproofing of the central water collection duct,

ii) verification and possible integration/restoration of the masonry lodgings in the extrados to the roof, in correspondence between the tiled covering and the rusticated lateral conglomerate,

iii) checking and eventual replacement or repair of the exhaust pipe inside the Grotto, iv) repair and consolidation of damaged masonry structures and vaulted areas, in relation to the structural consolidation that will be carried out on the underlying masonry bastion.

The designated local repair and reinforcement operations shall consist of:

-Execution of local scuci-cuci across the main lesions to reconnect the disconnected masonry structures;

-Deep closure of the cracks and filling injections across them with fluid mortar of hydraulic lime nhl 3.5 and pozzolana;

-Formation of "dry" metal seams with helical pins of $8 \mathrm{~mm}$ diameter inserted across the lesions with a "quincunx" arrangement.

Grotticina lorenese: for mouldings and plastered facade surfaces, the interventions will provide for a preliminary phase for securing the most precarious elements, by pre-consolidation with application of ethyl silicate brush and possibly with the use of temporary bandages.

Cleaning operations will follow, with removal of the particles and incohesive parts of the finish, by means of dry operations with vacuum cleaners and wisk brooms/brushes.

The following operations will concern the re-adhesion to the support of the detached areas by means of micro-injections of the hydraulic binder added with resins and grouting of the detachment contours.

Localized integrations will be carried out below the level of the larger areas of the gap, with drafting of the bottom and hinting of the volutes with a negative technique.

The more limited gaps, on the other hand, will be integrated in order to give a suitable aesthetic unity to the whole of the front. On the exposed mouldings, widespread applications of ethyl silicate based consolidating agent applied by brush on several occasions will be carried out.

The finishing phase will be carried out by retouching the lime glazes in the existing shades, and then a protective cycle based on siloxane will be applied, given in two stages. 


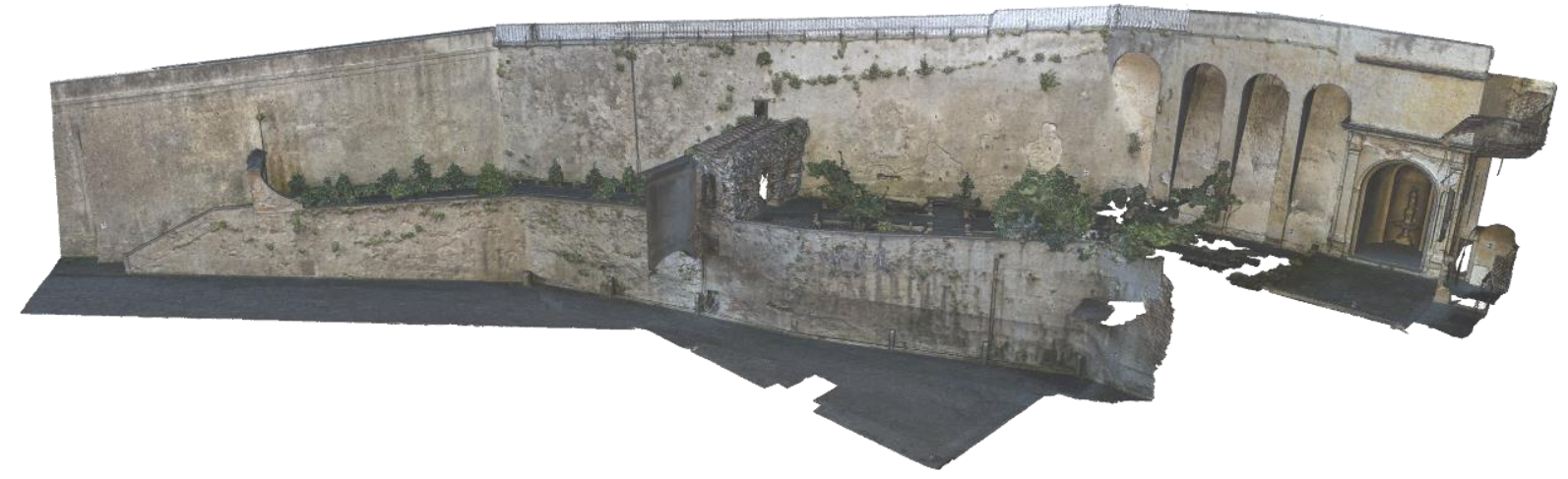

Figure 4. The mesh model

The internal marbles of the floor and fountain will be subject to conservation operations including a dry-cleaning phase of the incoherent deposits, and subsequent removal of coatings and localized concretions through applications with deionized water and pack cycles with tablets soaked in saturated solution of inorganic salts or ammonium carbonate. Micro-stuffing will be carried out with mortar loaded with marble powder in the areas of the gap and/or fracture, with final touch-up accompanied by watercolour.

\section{THE CAMELIE}

The Giardino delle Camelie is characterized by the presence of 49 specimens of different varieties of Camellia Japonica, including some dating back to the original nineteenth century (among others C.J. Candidissima, C.J. Rosa Simplex, C.J. Mathotiana Rubra, C.J. Pulcherrima, C.J. Warata).

In some specimens there are problems of physiological and phytosanitary nature, resulting from stress due to probable radical asphyxiation for the compaction and nature of the soil of limestone / clay associated with their excessive imbibition for the conformation of the Garden (adjacent to the embankment of Piazzale della Meridiana). These soil conditions, together with the anomalous climatic trends of recent years, have evidently favoured the onset of fungal diseases, which are currently being ascertained through the analysis of foliar samples and plant tissues.

In the same way, analyses are underway on soil samples to establish $\mathrm{pH}$ and texture, in order to calibrate future corrections with the addition of acidifying material and soil improvers that improve the grain size of the soil.

Among the interventions planned for the Giardino delle Camelie, there is the comeback from dry with disinfection of the cutting surfaces, the inoculation of antagonistic fungi, anthracnose and treatments with systemic copper products both through the root and on the aerial part, together with treatments with white oil to counteract the spread of cochineal.

In general, the preservation of the tree essences present is foreseen. However, for specimens that may be compromised from the point of view of plant health and vegetation, the appropriate interventions should be considered.

\section{CONCLUSION}

The case study analysed the historical and constructive events of a small but significant portion of the Boboli Gardens. The survey campaign, together with the geognostic surveys carried out, provided the useful elements to know and describe the aesthetic and formal characteristics of the garden, both in its surface (botanical, architectural and decorative) and spatial composition. In the continuation of the interventions that provide for the consolidation of damaged structures, works of conservation of architectural elements and surfaces, interventions to the historical water supply and the collection of camellia plants, it will be possible to document the operations on the 2D and 3D outputs. The possible repetition of the survey campaign at the end of the restoration could be used to document the interventions carried out and as a reference to monitor their effectiveness over time.

\section{ACKNOWLEDGEMENTS}

This work has been carried out under the GAMHer project: Geomatics Data Acquisition and Management for Landscape and Built Heritage in a European Perspective, PRIN: - Bando 2015, Prot. 2015HJLS7E

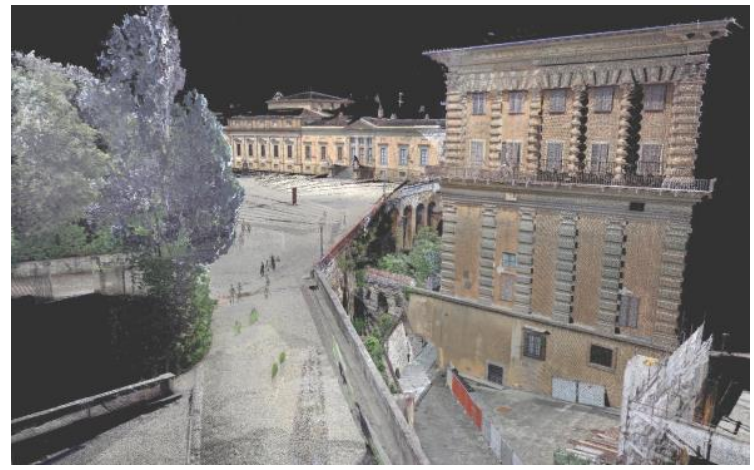

Figure 5. Point cloud, general view of the garden and the Piazzale della Meridiana

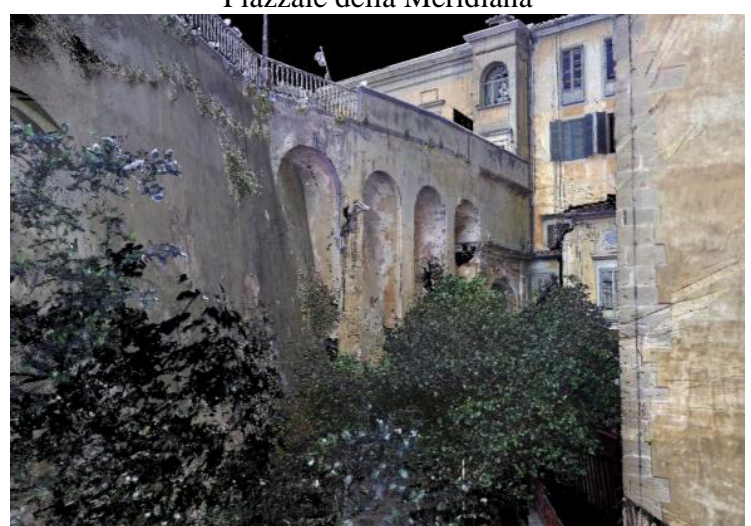

Figure 6. Point cloud, detail of the upper retaining wall 


\section{REFERENCES}

Baldini Giusti, L., 1991. Da Pitti a Boboli: l'arredo architettonico come mediazione fra interno ed esterno, in Boboli 90: Atti del Convegno Internazionale di Studi per la salvaguardia e la valorizzazione del Giardino (Firenze, 9-11 marzo 1989), a cura di C. Acidini Luchinat, E. Garbero Zorzi, Firenze, vol. II

Baldini Giusti, L. 2000 Gli ampliamenti del Palazzo: progetti e realizzazioni, in Palazzo Pitti. L'arte e la storia, Firenze.

Balletti, C., Guerra, F. 2015 The survey of cultural heritage: a long story. Rendiconti Lincei, 26, pp. 115-125

Boulanger, K., Bouatouch, K., \& Pattanaik, S. 2008. Rendering trees with indirect lighting in real time. In Computer graphics forum (Vol. 27, No. 4, pp. 1189-1198). Oxford, UK: Blackwell Publishing Ltd

Brandi, C., 1963 Teoria del restauro. Ed. di storia e letteratura.

Capecchi, G. 1993 Il Giardino di Boboli: un anfiteatro per la gioia dei granduchi, Firenze.

Capecchi, G. 2003 Prospetto di una parte del Real Palazzo di Residenza verso il giardino di Boboli, taglio della grotta detta di Moisè, XIX, Scheda Cat. 79, in Palazzo Pitti: la reggia rivelata, catalogo della mostra, Ministero dei Beni e delle Attività Culturali, Soprintendenza Speciale per il Polo Museale Fiorentino (Firenze, Palazzo Pitti, 7 dicembre 2003-31 maggio 2004), G. Capecchi, A. Fara, D. Heikamp, V. Saladino, (eds) Firenze.

Cappa D., Pettini, M. 2008 5. Il Giardino delle Camelie a Boboli, Livorno

Contini, A., Gori, O. 2004 Dentro la Reggia: Palazzo Pitti e Boboli nel Settecento, Firenze

De Carlo, L. 1989 Procedimenti di decodifica della cartografia storica per il rilievo delle aree verdi. In Immagine nel rilievo : atti del seminario di studio, Lerici, 10-11 maggio 1988/Roma, 20-22 febbraio 1989; Roma; Gangemi

Dezzi Bardeschi M., 1989 La Carta dei giardini storici otto anni dopo, in Ministero per i Beni Culturali e Ambientali - Ufficio Studi, Tutela dei giardini storici. Bilanci e prospettive, (a cura di V. Cazzato), Roma, Arti Grafiche NEMI

El-Hakim, S. F., Beraldin, J. A., Picard, M., \& Godin, G. 2004. Detailed 3D reconstruction of large-scale heritage sites with integrated techniques. IEEE Computer Graphics and Applications, 24(3), 21-29

Gori, O., 2003 Una corte dimezzata. La reggia di Pietro Leopoldo, in Vivere a Pitti: una reggia dai Medici ai Savoia, a cura di S. Bertelli e R. Pasta, Firenze, 291-349

Grussenmeyer, P., Alby, E., Assali, P., Poitevin, V., Hullo, J. F., \& Smigiel, E. 2011. Accurate documentation in cultural heritage by merging TLS and high-resolution photogrammetric data. In Videometrics, Range Imaging, and Applications XI (Vol. 8085, p. 808508). International Society for Optics and Photonics
ICOMOS https://www.icomos.org/en/charters-and-otherdoctrinal-texts

Kumazakia, R., \& Kunii, Y. 2016. 3d modeling of components of a garden by using point cloud data. International Archives of the Photogrammetry, Remote Sensing and Spatial Information Sciences, 5

Lamberini, D., Tamantini, M., 2013 La acque del Giardino di Boboli, Firenze, ed. Sillabe

Liang, H., Li, W., Lai, S., Zhu, L., Jiang, W., \& Zhang, Q. 2018. The integration of terrestrial laser scanning and terrestrial and unmanned aerial vehicle digital photogrammetry for the documentation of Chinese classical gardens-A case study of Huanxiu Shanzhuang, Suzhou, China. Journal of Cultural Heritage, 33, 222-230

Ministero per Beni e le Attività Culturali, Soprintendenza per i Beni Ambientali e Architettonici per le Province di Firenze, Prato e Pistoia, Giardino di Boboli Master Plan. Paesaggio e architettura, a cura di Giorgio Galletti, con la consulenza dello studio Elisabeth Banks Associates e la collaborazione di L. Stefanini (stampa in digitale), 1999

Nizzi Grifi, A. 2003 La Grotta nel Giardino delle Camelie, in Il Giardino di Boboli, a cura di L. M. Medri, Firenze, pag. 102

Sette, M.P., Accorsi, M.L. 2016 Il verde nel paesaggio storico di Roma : significati di memoria, tutela e valorizzazione. Quasar ISBN: 9788871407654;

Tesi V., Tucci G., Bonora V., Conti A., Fiorini L., 2017. Laser scanning and modelling of barely visible features: the survey of the Grotto of the Animals at the Villa of Castello (Florence). ISPRS Archives - Geomatics \& Restoration, XLII-5/W1, pp. 343-349

Tucci, G. Note sul rilievo dei giardini. Giusti MA (cur.), I tempi della natura. Restauro e restauri dei giardini storici. Firenze: EDIFIR, 1999, 39-46

Tucci, G., Conti, A., Fiorini, L. 2013 Scansione laser per il rilievo dei giardini storici. GEOmedia, 17(6)

Zangheri L. 2008 Il restauro dei giardini storici in Italia dal 1980 in Tomasi Tongiorgi, L. and Zangheri, L. eds. Bibliografia del giardino e del paesaggio italiano, 1980-2005. Vol. 20. Olschki 